\title{
PREVENTION OF THROMBOPHLEBITIS IN SPINAL INJURY PATIENTS
}

\author{
By E. van Hove \\ Department of Physical Medicine and Orthopedics, University Hospital, \\ De Pintelaan I35, B 9000 Gent, Belgium
}

Abstract. This paper deals with the prevention of thrombophlebitis by means of massage and elastic stocking compression. In a group of 26 patients no evidence of thrombophlebitis or pulmonary embolism was observed.

Key words: Thrombophlebitis; Prevention; Massage; Elastic stocking compression.

\section{Introduction}

THE occurrence of thrombophlebitis constitutes a serious complication in the treatment of paraplegics and tetraplegics. Its incidence is estimated at 25 per cent (Silver, I974) and I7 per cent (Watson, I974), whilst pulmonary embolism accounts for Io per cent. The mortality rate is 2.5 per cent (Watson, 1974). In the last few years anticoagulant therapy was systematically instituted at the onset of the lesion, thus reducing the prevalence of thrombophlebitis to 5 or ro per cent (Hachen, I974 and Silver, I974).

The general causes of thrombophlebitis are cited in the conventional Virchow triad, i.e. vascular injury, reduced blood flow velocity and altered coagulation conditions, the second being the main causative factor in paraplegic and tetraplegic patients, this because of failure of the active calf pump. The risk of venous stasis is further enhanced by pressure of the calf muscles against the bed (Guttmann, I973).

To be effective anticoagulant therapy must be started from the beginning of the traumatic lesion and be continued for some 2 or 3 months. Haemothorax, gastric and duodenal ulcer, severe renal and liver disease, uncontrolled hypertension and head injury are however substantial contraindications to such a treatment regimen (Guttmann, I973).

In view of the relatively high incidence of thrombophlebitis in paraplegic patients and with regard to the above contraindications, inherent to anticoagulant therapy, we thought it interesting to test the effectiveness of a purely physical treatment, consisting of massage and elastic stocking compression.

\section{Material and Methods}

Forty-one consecutive patients were included in this study (Table I), all admitted on the day of the accident with complete paraplegia or tetraplegia of traumatic origin. No prophylactic anticoagulant therapy was installed.

The first Is patients of this group served as controls (Control Group ATable II) and received following treatment twice a day: passive mobilisation of the lower extremities, active mobilisation of the upper extremities, respiration therapy and nursing (turning of the patient every 2 hours). The second group (Test Group $\mathrm{B}$ - Table II) was made up of 26 patients who were given, in addition, massage of the lower extremities (twice daily) and permanent elastic stocking compression. 
TABLE I

Total group of patients

\begin{tabular}{ll}
\hline Number & $4 \mathrm{I}$ \\
Mean age & 35 \\
Sex & $33 \delta-8 \%$ \\
Lesion & Traumatic-complete \\
Localisation & Cervical I2-dorsal 20-lumbar 9 \\
\hline
\end{tabular}

\section{TABLE II}

\begin{tabular}{lll}
\hline & \multicolumn{1}{c}{ Control group (A) } & \multicolumn{1}{c}{ Test group (B) } \\
Number & I5 & 26 \\
Age & $34(\mathrm{I} 6-60)$ & $36(\mathrm{I} 4-80)$ \\
Sex & I2 $5-3+$ & $210-5+$ \\
Obese & 7 & I2 \\
Localisation & Cerv. 2, dors. I0, lumb. 3 & Cerv. I0, dors. I0, lumb. 6 \\
Treatment & Anticoagulants: none & Anticoagulants: none \\
& Passive mobilisation & Passive mobilisation \\
& Nursing & Nursing \\
& Respiration therapy & Respiration therapy \\
& & Massage lower extremities \\
& & Elastic stocking compression \\
\hline
\end{tabular}

Massage consisted mainly of centripetal draining manipulations exerted at the calf and hamstring muscles. It was started on the first day of the trauma and maintained throughout the entire bedridden stage. The elastic stockings covered the entire leg, from the toes up to the thighs. The bandages were applied beginning from the basis of the toes and wound in pronation turns spirally round the leg, including the thigh.

Twice a day circumference of calf and thigh was measured in all $4 \mathrm{I}$ patients and the clinical signs of thrombophlebitis were looked for.

\section{Results}

In Control Group A six patients (i.e. 40 per cent) were found to have thrombophlebitis. Pulmonary embolism occurred in two cases (i.e. I3 per cent) (Table III).

In Test Group B no evidence of thrombophlebitis or pulmonary embolism was observed.

The members of Control Groups A and Test Group B were matched for age, sex and physical condition (see Table II), factors that might predispose to thrombophlebitis (Watson, I974). However, closer examination of the controls who turned out to be positive (see Table III) yields some striking information: the left leg was most frequently affected (five out of six), which is in agreement with the findings of Watson (I974), and five out of the six positive patients were obese, whereas this was only true for two patients of the group which proved to be negative. Age did not seem to be a relevant factor. 
TABLE III

\begin{tabular}{|c|c|c|c|}
\hline & \multicolumn{2}{|c|}{ Control group (A)-I 5 patients } & \multirow[t]{2}{*}{ Test group (B) } \\
\hline & Positive $(\mathrm{A}+)$ & Negative $(\mathrm{A}-)$ & \\
\hline Number & 6 & 9 & 26 \\
\hline Age & $33(19-60)$ & $35(16-60)$ & $36(14-80)$ \\
\hline Sex & $45-2+$ & $83-1+$ & $210-5 q$ \\
\hline Localisation & - & - & Cerv. Io, dors. Io, lumb. 6 \\
\hline Obese & 5 & 2 & $\mathrm{I} 2$ \\
\hline Thrombophlebitis & $6(40 \%)$ & - & - \\
\hline Side & left 5 , right $I$ & - & - \\
\hline Pulmonary embolism & $2(13 \%)$ & - & - \\
\hline
\end{tabular}

\section{Discussion}

At first sight the 40 per cent incidence of thrombophlebitis in Control Group A might seem very high in comparison to the findings of other authors, but the way of diagnosing, the difference in atmospheric conditions and circumstances of life may account for this discrepancy.

The proposed prophylactic physical treatment is mainly directed to venous stasis. Passive mobilisation permits preservation of articular mobility and results in activation of the blood flow in paraplegic patients (Seifert et al., I972). system.

Massage increases lymphflow (Pflug, I975) and thus supports the vascular

Elastic stockings have long since been applied successfully in postoperative patients. A compression level of io to $20 \mathrm{~mm} \mathrm{Hg}$ is considered as optimal for general hospital use (Ginsberg, 1967).

It is however fundamental that above triad, aiming at prevention of thrombophlebitis, is started immediately after the traumatic lesion, the same remark holding also for the prophylactic anticoagulant therapy regimen. Finally, all therapeutic measures should be installed at a frequency rate of twice a day.

\section{Conclusion}

The present study suggests that passive mobilisation, massage and elastic stocking compression, started from the first day of the traumatic lesion at a frequency rate of twice a day, provide adequate prophylaxis for thrombophlebitis and pulmonary embolism in the paraplegic patient. Further investigations should decide upon the value of a similar treatment, as compared to anticoagulant drug therapy.

\section{SUMMARY}

The incidence of thrombophlebitis was examined in a series of $4 \mathrm{I}$ paraplegics and tetraplegics of traumatic origin, none of whom was receiving prophylactive anticoagulant therapy at the time of study.

In a first group of 15 patients (Control Group A) six cases of thrombophlebitis and two cases of pulmonary embolism were diagnosed. 
In a second group of 26 patients (Test Group B), treated by massage and elastic stocking compression, no evidence of thrombophlebitis or pulmonary embolism was observed.

\section{RÉSUMÉ}

Afin de déterminer la fréquence des thrombophlébites, nous avons examiné une série de 4I paraplégiques et tétraplégiques d'origine traumatique, aucun ne se trouvant sous d'anticoagulants préventifs.

Dans un premier groupe de 15 patients on a diagnostiqué 6 cas de thrombophlébite et 2 cas d'embolie pulmonaire.

Dans un second groupe de 26 patients, qui étaient soumis à des séances de massage et à l'application de bandages compressifs, aucun cas de thrombophlébite ni d'embolie polmonaire n'a pu être diagnostiqué.

\section{ZUSAMMENFASSUNG}

Die Häufigkeit von Thrombophlebitis ist in einer Reihe von 4I traumatisch bedingten Paraplegikern und Tetraplegikern bei denen keine Antikoagulantienprophylaxe eingesetzt wurde, untersucht worden.

In einer ersten Gruppe von I5 Patienten sind 6 Fälle von Thrombophlebitis und 2 Fälle von Lungenembolie diagnostiziert worden.

In einer zweiten Gruppe von 26 Patienten, die mit Massage und elsticschen Strümpfen behandelt wurden, haben sich keine Fälle von Thrombophlebitis oder Lugenembolie ergeben.

\section{REFERENCES}

AdAR, R. \& SAlzman, E. W. (1975). Treatment of thrombosis of veins of the lower extremities. New England fournal of Medicine, 292, 348-350.

Ginsberg, M., Miller, M. \& McElfatrick, G. C. (1967). The use of inflatable plastic splints. F. Am. Med. Assoc., 200, I80-181.

Guttmann, L. (1973). Spinal Cord Injuries, ist edn. Blackwell Scientific Publications, Oxford.

HaChen, H. J. (1974). Anticoagulant therapy in patients with spinal cord injury. Paraplegia, 12, I76-I 87.

PfLUG, J. J. (I975). Intermittent compression in the management of swollen legs in general practice. The Practitioner, 215, 69-76.

Salzman, E. W. (1975). Diagnosis of deep vein thrombosis. Thrombosis Diathesis Haemorrhagica, XXXIII, 457-463.

Seifert, J., Lob, G., Stoephasius, E., Probst, J. \& Brendel, W. (I972). Blood flow in muscles of paraplegic patients under various conditions measured by a double isotope technique. Paraplegia, 10, I85-191.

SILVER, J. R. (1974). The prophylactic use of anticoagulant therapy in the prevention of pulmonary emboli in one hundred consecutive spinal injury patients. Paraplegia, 12, I 88-196.

Tillberg, B. (1974). Prophylaxis of postoperative venous thrombosis. Acta Orthopaedica Scandinavica, suppl. I 58.

Watson, N. (1974). Anticoagulant therapy in the treatment of venous thrombosis and pulmonary embolism in acute spinal injury. Paraplegia, 12, 197-201. 